\title{
A Comparative Study to Determine the Outcome of Supracondylar Fracture of Humerus in Children Treated with Percutaneous Cross Pinning Versus Two Lateral Pinning
}

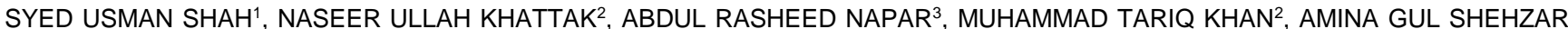 \\ $\mathrm{KHAN}^{2}$, SAMI ULLAH ${ }^{2}$ \\ ${ }^{1}$ Assistant Professor Orthopedics, Ayub Teaching Hospital, Abbottabad \\ ${ }^{2}$ TMO Orthopedics, Ayub Teaching Hospital, Abbottabad \\ ${ }^{3}$ Assistant Professor Orthopedics Surgery Khairpur Medical College, Khairpur Mir's Sindh \\ Corresponding author: Naseer ullah Khattak, Email: nasirkhattak1993@gmail.com, Cell: +92343-9506554
}

\begin{abstract}
Objective: Analysis and assessment of anatomical refurbishment with the use of percutaneous cross pinning versus two lateral pinning and to determine the functional consequences of these procedures, to evaluate the hurdles faced in these treatment methodologies, and the comparison between the patient acceptances in both methods.

Methods: This research was a comparative cross-sectional analysis which was conducted at Orthopedics department of Ayub Teaching Hospital Abbottabad for duration of six months i.e from March 2021 to August 2021. The sample size for the research was 50 patients who were admitted both at the (outpatient department) OPD and in the emergency ward. All the patients were clinically examined carefully and thoroughly, and all of their details were recorded. Base line investigations and X-rays were performed of every patient.

Results: Percutaneous cross pinning or two lateral pinning methods were used to treat 50 patients suffering from supracondylar fracture of humerus. Two groups were formed, each had 25 patients. Group A consisted of patients were treated from PCP, while group B patients were treated from TLP. Among the patients of Group, A, $20(80 \%)$ were male, $5(20 \%)$ were female, with a female: male ratio of $1: 5$, while in group B patients, $22(88 \%)$ were male, $3(8 \%)$ were female, with a female: male ratio of 1:8. The average age of both the groups was $7.30+3.30$ years. The most prominent reason of fracture in the designed study was fall during playing (54\%), $24 \%$ patients reported falling from bicycle, while only $22 \%$ patients had fallen from trees, the height of which was around 5-7 feet. Postero-medial displacement was observed in $66 \%$ patients, while Postero-lateral displacement was observed in $34 \%$ patients. Among the list of complications, in TLP, $8 \%$ patients suffered from superficial pin tract infection, $12 \%$ patients suffered from non-union, and $4 \%$ patients had K-wire migration and $4 \%$ had Cubitus varus. On the other hand, in PCP group patients, one patient developed superficial pin tract infection, $8 \%$ patients had nonunion, and $4 \%$ patients had K-wire migration. When the results were analyzed using the Flynn criteria, they were excellent (48\% group $\mathrm{A}$ patients versus $36 \%$ patients of group B), $32 \%$ patients in group A had good results and $28 \%$ in group B, $20 \%$ patients of group $B$ versus $12 \%$ patients of group $A$ were regarded as fair, and $8 \%$ patients of group $A$ versus $16 \%$ patients of group $B$ were considered as poor. The patients who carried angle loss were $12 \%$ of group A versus $24 \%$ of group B, and who complained about loss of motion were $15 \%$ patients of group A versus $25 \%$ patients of group B were classified according to Flynn criteria Conclusion: Percutaneous cross pinning is concluded as the better, and more predictable treatment method in terms of management, as compared to two lateral pinning method to treat the Supra-condylar fractures.

Key Words: Percutaneous cross pinning, two lateral pinning, supra-condylar fracture, humerus
\end{abstract}

\section{INTRODUCTION}

Among the elbow injuries of children, the humerus bone undergoing the supra-condylar fracture is the most common injury. In children, it accounts for $3 \%$ in all sort of fractures ${ }^{1-2}$. Although the frequency of getting supra-condylar fractures gets rare as the kids proceeds towards the adolescent $\mathrm{age}^{3-4}$. The mean age group which is affected by this fracture is $71 / 2$ years. Children face these fractures during the first 10 years of their lives, and the frequency gets a peak at around 8 years ${ }^{5}$. This sort of fracture usually happens due to falling upon the hand which is outstretched on extended elbow 6 . The displacement of distal fragment posteriorly is observed in more than $95 \%$ cases which are of extension type, while only less than $5 \%$ cases undergo anterior displacement of distal fragment in the flexion type of cases $^{6}$. Gartland's criteria is used to classify the fractures into fractures in which there is no displacement (type 1), fractures with partial displacement here the posterior cortex was found to be intact (type 2), and the fractures in which there was complete displacement (type 3). The type 3 fractures involved the injuries of neurological vessels, where the complications were observed because of the mal-union, compartment syndrome, iatrogenic neurovascular injury, or elbow stiffness in the treatment. The treatment depends upon the degree on which displacement occurs ${ }^{7-8}$. The methods that are currently in use, and preferred to treat are percutaneous pinning method, and the closed reduction method. The open reduction method is recommended in fractures which are irreducible, injuries that are open, and compromised vessels. The complete regimen includes flex manipulation and casting, traction, extension manipulation and casting, percutaneous pinning and closed reduction method by
Kirchner wires, internal fixation, and open reduction ${ }^{9}$. The surgical therapy becomes crucial because of the deep-rooted instability, hurdles to achieve reduction, and as there is an expected loss in the movement range which is due to keep elbow in extension for a quite longer $\operatorname{span}^{10}$. To skip the issue of compromised vessels, and the compartment syndrome, emergency treatment is recommended. Different studies have recommended the percutaneous pinning as the method of choice, however, there are certain studies which differs from the idea ${ }^{11}$. The idea behind this study is the analysis of the refurbishment of anatomy when percutaneous pinning is carried out, its consequences in terms of function, the obstacles during the treatment, and the comparison of this method with the two lateral pinning method, in terms of acceptance by the patients.

\section{MATERIALS AND METHODS}

This research was a comparative cross-sectional analysis which was conducted at Orthopedics department of Ayub Teaching Hospital Abbottabad for duration of six months i.e from March 2021 to August 2021. The designed study is a comparative analysis between the two methods of treatments i.e., percutaneous pinning group, and two lateral pinning group to treat the supra-condylar fractures of humerus. University's ethical review committee gave the ethical approval to conduct this study. Children with the age range of 4-14 years which had the displaced and closed supracondylar fractures during the 72 hours of having the fracture, regardless their gender, were included. Cases admitted at the OPD and emergency department both were included. Patients having mal-united fractures which had neurological disability, 
fractures due to some kind of pathological illness, fractures which belong to some very serious abdominal and chest injuries, open fracture, fractures which compromise the vessels, compound fractures, or the supra-condylar fracture of humerus (the extension type) which had undergone vascular injury were excluded from the study. For this study, two groups were formed named as Group A, and Group B. The group A had 25 patients for percutaneous cross pinning (PCP) while group $B$ had 25 patients of two lateral pinning (TLP). All the patients were extensively examined clinically. Their major or minor head injuries were detected. Base line investigations were carried out on all patients. Six months follow up with the interval of initially two weeks, then two months, and then one month interval for the upcoming four months. To analyze any sort of complications, removal of K-wires was ensured after six weeks. A specified proforma was prepared and the data was entered in it. SPSS version 21.0 was used to analyze the data. Gender, and mode of injury were the absolute variables, and presented in frequencies, while age which is the continuous variable was defined with mean and standard deviation. To assess the complications which happened post-surgery in both the groups, chi square test was applied, and the results were compared as described in the Flynn criteria. $P$ value less 0.05 was set as the level of significance.

\section{RESULTS}

Percutaneous cross pinning or two lateral pinning methods were used to treat 50 patients suffering from supra-condylar fracture of humerus. Two groups were formed, each had 25 patients. Group A consisted of patients were treated from PCP, while group $B$ patients were treated from TLP. Among the patients of Group, A, $20(80 \%)$ were male, $5(20 \%)$ were female, with a female: male ratio of $1: 5$, while in group B patients, $22(88 \%)$ were male, $3(8 \%)$ were female, with a female: male ratio of $1: 8$. The average age of both the groups was $7.30+3.30$ years. The most prominent reason of fracture in the designed study was fall during playing (54\%), $24 \%$ patients reported falling from bicycle, while only $22 \%$ patients had fallen from trees, the height of which was around 5-7 feet. Posteromedial displacement was observed in $66 \%$ patients, while Posterolateral displacement was observed in $34 \%$ patients.

Post Operative Complications Among Patients Are Given N Table-I

\begin{tabular}{|c|c|c|c|c|c|}
\hline \multirow[t]{2}{*}{ Complications } & \multicolumn{2}{|c|}{ TLP Group B } & \multicolumn{2}{|l|}{ PCP Group A } & \multirow{2}{*}{$\begin{array}{l}\text { P- } \\
\text { Value }\end{array}$} \\
\hline & $\begin{array}{l}\text { No. of } \\
\text { Patients }\end{array}$ & $\%$ & No. of Patients & $\%$ & \\
\hline $\begin{array}{l}\text { Superficial pin } \\
\text { tract infection }\end{array}$ & 2 & $8 \%$ & 1 & $4 \%$ & \multirow{5}{*}{0.601} \\
\hline Non-Union & 3 & $12 \%$ & 2 & $8 \%$ & \\
\hline $\begin{array}{l}\text { latrogenic ulnar } \\
\text { nerve injury }\end{array}$ & 0 & $0 \%$ & 0 & $0 \%$ & \\
\hline K-wire migration & 1 & $4 \%$ & 1 & $5 \%$ & \\
\hline Cubitus varus & 1 & $4 \%$ & 0 & $0 \%$ & \\
\hline
\end{tabular}

Among the list of complications, in TLP, $8 \%$ patients suffered from superficial pin tract infection, $12 \%$ patients suffered from nonunion, and $4 \%$ patients had $\mathrm{K}$-wire migration and $4 \%$ had Cubitus varus. On the other hand, in PCP group patients, one patient developed superficial pin tract infection, $8 \%$ patients had nonunion, and $4 \%$ patients had K-wire migration (Table 1 ).

When the results were analyzed using the Flynn criteria, they were excellent (48\% group A patients versus $36 \%$ patients of group B), $32 \%$ patients in group $A$ had good results and $28 \%$ in group B, $20 \%$ patients of group B versus $12 \%$ patients of group $A$ were regarded as fair, and $8 \%$ patients of group $A$ versus $16 \%$ patients of group B were considered as poor (Table 2).

The patients who carried angle loss were $12 \%$ of group A versus $24 \%$ of group $B$, and who complained about loss of motion were $15 \%$ patients of group A versus $25 \%$ patients of group B (Table 3), were classified according to Flynn criteria.

\begin{tabular}{|c|c|c|c|c|c|}
\hline \multirow{2}{*}{ Results } & \multicolumn{2}{|c|}{ TLP Group B } & \multicolumn{2}{|l|}{ PCP Group A } & \multirow{2}{*}{$\begin{array}{l}\text { P- } \\
\text { Value }\end{array}$} \\
\hline & $\begin{array}{l}\text { No. of } \\
\text { Patients }\end{array}$ & $\%$ & No. of Patients & $\%$ & \\
\hline Excellent & 9 & $36 \%$ & 12 & $48 \%$ & \multirow{4}{*}{0.741} \\
\hline Good & 7 & $28 \%$ & 8 & $32 \%$ & \\
\hline Fair & 5 & $20 \%$ & 3 & $12 \%$ & \\
\hline Poor & 4 & $16 \%$ & 2 & $8 \%$ & \\
\hline
\end{tabular}

\begin{tabular}{|c|c|c|c|c|c|}
\hline \multirow[b]{2}{*}{ Outcome } & \multicolumn{2}{|c|}{ TLP Group B } & \multicolumn{2}{|l|}{ PCP Group A } & \multirow{2}{*}{$\begin{array}{l}\mathrm{P}- \\
\text { Value }\end{array}$} \\
\hline & $\begin{array}{l}\text { No. of } \\
\text { Patients }\end{array}$ & $\%$ & No. of Patients & $\%$ & \\
\hline $\begin{array}{l}\text { Carrying } \\
\text { angle loss }\end{array}$ & 6 & $24 \%$ & 3 & $12 \%$ & \multirow{2}{*}{0.002} \\
\hline $\begin{array}{l}\text { Loss of } \\
\text { motion }\end{array}$ & 3 & $12 \%$ & 2 & $8 \%$ & \\
\hline
\end{tabular}

\section{DISCUSSION}

In this study, the female to male ratio of group 1 was 1:5 in comparison to the group 2 where this ratio was $1: 8$. As males were more who had higher rates of having fractures because they are more related with the activities happening outdoors as compared to females. As reported in the study conducted by Babar (15) $17 \%$ patients were girls, and $83 \%$ were boys, in which the female to male ratio was around 1:5 $12-13$. Age was quite varied in both the groups, the range of which was 3-13 years where the average age was $7.30+3.30$ years. It was observed that during the first decade of one's life, the likelihood of having this kind of fracture is more common. Other studies conducted $(9,10,15)$, had also reported that there is a very high frequency of fractures in age before adolescence ${ }^{14}$. The study of Ostoji $Z$ had observed the age range of 1 to 14 years with an average age of 6.7 years. Mostly, these kinds of fractures are because of falling upon the extended elbow of the outstretched hand. Posterior displacement of distal fragment was quite high i.e., in more than $95 \%$ cases in the class of extension, while in the flexion class, less than $5 \%$ cases had anterior displacement. There were patients $54 \%$ who had fall during playing as their reason of fracture, $24 \%$ patients had fallen from bicycle, and $22 \%$ patients had fallen from tree. The study of Fransworth et al had explained that the falling from a height was the major reason in $70 \%$ cases. The extension of fractures was described by Gartland in three major classes which was based upon the extent of displacement ${ }^{15-16}$. Taking that as reference, we observed the presence of class III A posteromedial displacement in $66 \%$ patients while there were only $34 \%$ patients which belong to the posterolateral displacement (class III B). Noor Akbar Sial explained that 29 fractures belonged to grade II (51.7\%), and 27 patients $(48.21 \%)$ had grade III fractures ${ }^{17}$. In children, the fractures which were of supra-condylar type in the humerus are the most common cause of injuries, where in a great many cases entire displacement of the fragments is observed. It is very likely that the problems of vessels can easily be avoided. Although the major problem of supra-condylar fracture is Cubitus-varus of humerus in teenagers ${ }^{18}$. Initially these can be treated without surgery, where reduction and fixation is not required. The incidence can vary from $4 \%$ to $58 \%$ cases. Improper reduction, improper fixation, or the growth disturbances occur at the bottom of the humerus can be the cause of the deformity. It is suggested by multiple authors that deformity is usually due to the improper reduction ${ }^{19}$. This often leaves a remaining rotatory malformation which can form a medical tilt which could result into varus distortion. In the present study, Cubitus-varus was observed in only $4 \%$ patients of group B, while there weren't any in group A. Extensive studies performed on the supra-condylar fracture of humerus explains the PCP is the preferred method of choice in the fractures of extension type, even when the minimally displaced 
ones are concerned ${ }^{20}$. As suggested by some authors immobilization and closed reduction is associated with the late and early snag ration, inclusion of Volkmann ischemic contracture, and the Cubitus-varus. In the study by Antoine de Gheldere $5.8 \%$ patients had median nerve injury as described in Gartland type II, and $2.5 \%$ present in type III of Gartland. Ulnar nerves injury was in $2.5 \%$ patients according to Gartland type II. The designed study suggested that the patient that carry angle loss were $24 \%$ of group $\mathrm{B}$ and $12 \%$ of group $A$, whereas $12 \%$ patients of group B, and $8 \%$ of group A had loss of motion. The study conducted by Nedim Smajic reported the presence of loss of motion in the elbow which was injured, when it was compared with the healthy individuals after the completion of physical treatment. It was of $8.83 \pm 11.03^{\circ}$ in the first group, and $14.43 \pm 12.68^{\circ}$ in the other group ${ }^{20}$. It was supposed to be the objective of the treatment is to obtain a cosmetic, functional, and acceptable extremity which had the motion in normal range. To assess the supra-condylar fracture healing Flynn's criteria is used, which analyze the carrying angle and loss of motion as a cosmetic factor, and a functional factor respectively. It estimates the functional and the cosmetic factor very particularly, where the patient can have some deformity but the function is good, or the function could be bad but with no deformity. The carrying angle and motion range depends upon the clinical loss, which means that the patients who have cosmetic outcomes which are good enough, or have good function, they would be regarded as fair $^{21-22}$.

\section{CONCLUSION}

To conclude, it can be said that the treatment by percutaneous cross pinning is better as compared the two lateral pinning when it comes to treat the supra-condylar fractures of humerus. It was found that these types of fractures are more common in boys, management of PCP is better, and also its results are more predictable than TLP. The complication rate is low and one can become familiar with the technique easily.

\section{REFERENCES}

1. Uludağ A, Tosun HB, Aslan TT, Uludağ Ö, Gunay A. Comparison of three different approaches in pediatric gartland type 3 supracondylar humerus fractures treated with cross-pinning. Cureus. 2020 Jun;12(6).

2. Afaque SF, Singh A, Maharjan R, Ranjan R, Panda AK, Mishra A. Comparison of clinic-radiological outcome of cross pinning versus lateral pinning for displaced supracondylar fracture of humerus in children: A randomized controlled trial. Journal of clinical orthopaedics and trauma. 2020 Mar 1;11(2):259-63.

3. Dhankhar K, Bhati M, Singh D, Bishnoi R, Rulania H. Functional and Radiological Outcome of Closed Reduction and Percutaneous Pinning Of Supracondylar Fracture of Humerus In Children Aged 5 To 15 Years: A Prospective Interventional Study.

4. Kumar EK, Bari A. A comparative study of clinical outcome of surgical management of supracondylar fracture of humerus in children with crossed (Medial and Lateral) k-wire fixation and two lateral k-wire fixation. International Journal of Orthopaedics. 2020;6(1):53-7.

5. Jagiasi JD, Ubale TV, Dole GB, Upadhyaya MR. A comparative study of percutaneous pinning techniques (Cross $\mathrm{K}$ wire vs lateral $\mathrm{K}$ wire) for Gartland type III pediatric supracondylar fracture of the humerus. International Journal of Orthopaedics. 2020;6(3):226-9.

6. Trung DT, Le Van N, Huu VN, Nguyen CD, Ngoc HN, Nga VT, Dinh TC. Closed Reduction and Percutaneous Pinning for Supracondylar
Fractures of Humerus in Vietnamese Children. Open access Macedonian journal of medical sciences. 2019 Dec 30:7(24):4194.

7. Vikram A. Functional outcome of displaced supracondylar fracture humerus in children treated by closed reduction and percutaneous pinning with Kirchner wires: An observational study. International Journal of Orthopaedics. 2019:5(4):757-61.

8. Rupp M, Schäfer C, Heiss C, Alt V. Pinning of supracondylar fractures in children-Strategies to avoid complications. Injury. 2019 Jun 1;50:S2-9.

9. Sapkota K, Wahegaonkar K, Ranjeet N, Thapa P, Thapa UJ, Onta $\mathrm{PR}$. Comparison of cross pinning versus lateral three pins in type three supracondylar fracture of distal humerus in children. Asian Journal of Medical Sciences. 2019 Mar 1:10(2):58-61.

10. Bhandari A, Bhati A, Girotra P, Dawar H. Outcomes of K-wire pinning in supracondylar fractures of humerus in pediatric age group: $\mathrm{A}$ comprehensive study. International Journal of Orthopaedics. 2020;6(4):949-53

11. Catena N, Calevo MG, Fracassetti D, Moharamzadeh D, Origo C, De Pellegrin M. Risk of ulnar nerve injury during cross-pinning in supine and prone position for supracondylar humeral fractures in children: a recent literature review. European Journal of Orthopaedic Surgery \& Traumatology. 2019 Aug;29(6):1169-75.

12. Eguia F, Gottlich C, Lobaton G, Vora M, Sponseller PD, Lee RJ. Midterm Patient-reported Outcomes After Lateral Versus Crossed Pinning of Pediatric Supracondylar Humerus Fractures. Journal of Pediatric Orthopaedics. 2020 Aug 7:40(7):323-8.

13. Abubeih HM, El-Adly W, El-Gaafary K, Bakr H. Percutaneous crosspinning versus two lateral entry pinning in Gartland type III pediatric supracondylar humerus fractures. The Egyptian Orthopaedic Journal. 2019 Jan 1;54(1):52.

14. Ali M, Siddiq K, Makki MK, Baig MS, Khan GQ, Riaz S. Outcome of Percutaneous pinning among Children with displaced Supracondylar Fracture of the Humerus. Journal of Sheikh Zayed Medical College (JSZMC). 2020 Jul 25;11(2):28-32.

15. Jain S, Agrawal S, Banshiwal RC. Comparative study of posterior intrafocal with lateral pinning versus cross pinning for extension type supracondylar fracture humerus in children.

16. Hegazy MO, Meselhy MA, EL-Nabasy AA. Lateral Divergent Pinning Versus Lateral Parallel Pinning in Management of Supracondylar Fractures of the Humerus in Children. Benha Journal of Applied Sciences. 2020 Sep 1;5(6 part (2)):1-6.

17. Rakha A, Khan RD, Arshad A, Khan ZA, Ahmad S, Mahmood S. Comparison of Efficacy Between Open and Close Reduction in Supracondylar Fracture of Humerus in Children using Flynn's Criteria. Annals of Punjab Medical College (APMC). 2020 Jul 1;14(1):32-6.

18. Sankar S, D'Souza JJ, Debuka E, Vyas T, Jagani N. The functional outcome of displaced supracondylar fracture humerus in children treated by open reduction and internal fixation by lateral pins compared to medial and lateral pins: A prospective study.

19. Gholap A, Wokhlu A, Gholap P. Gartlands type III supracondylar humerus fractures-cross $k$-wiring versus lateral $k$-wiring: A preliminary study. International Journal of Orthopaedics. 2020;6(1):1259-62.

20. Li J, Rai S, Tang X, Ze R, Liu R, Hong P. Surgical management of delayed Gartland type III supracondylar humeral fractures in children: a retrospective comparison of radial external fixator and crossed pinning. Medicine. $2020 \mathrm{Mar} ; 99(10)$.

21. Taleb H, Tabrizi A, Nouri A. Risk factors of loss reduction after percutaneous fixation in supracondylar humerus in pediatric: a descriptive-analytical study. Studies in Medical Sciences. 2020 Oct 10;31(8):576-81.

22. Sahoo BS, Chand DK. Results of treatment of displaced supracondylar fractures of humerus in children by closed reduction and percutaneous pinning. International Journal of Orthopaedics. 2019;5(4):08-12. 